\title{
Economic Diversity and Employment Levels in Italian Provinces over the Period 1951-2001: Does a Recurrent Industrial Pattern Exist?
}

\author{
Alessandro Marra ${ }^{1}$, Vittorio Carlei ${ }^{2}$, Alessandro Crociata ${ }^{2}$ \\ ${ }^{1}$ Università degli Studi “G. D’Annunzio” di Chieti e Pescara, Facoltà di Scienze Manageriali and Dipartimento di \\ Metodi Quantitativi e Teoria Economica (DMQTE); GRIF (Gruppo di Ricerche Industriali e Finanziarie) - Fabio \\ Gobbo, LUISS Guido Carli, Rome \\ ${ }^{2}$ Università degli Studi “G. D’Annunzio” di Chieti e Pescara, Facoltà di Scienze Manageriali and Dipartimento di \\ Metodi Quantitativi e Teoria Economica (DMQTE); SEMEION, Rome. \\ E-mail:amarra@unich.it. \\ Received April 4, 2011; revised May 50, 2011; accepted June 3, 2011
}

\begin{abstract}
Economic diversity is crucial to explain how geographic areas grow and evolve: economic diversity facilitates the transmission of ideas (through knowledge spillovers) and the outsourcing of activities (city-nurseries). In this paper we focus on these theoretical perspectives and examine the industry structure and growth of Italian provinces. We use data on employment levels in 47 economic sectors in 103 provinces and measure their degree of diversity over the period 1951-2001. By taking into account both provincial size (i.e., employment levels) and temporal dimension we test whether economic initiatives benefit from being localised in areas that are highly diversified from an industrial point of view. After confirming the relevance of economic diversity we investigate the industry pattern that boosted growth in the largest (in terms of number of employees) provinces in our sample. Our results confirm the Jacobs' intuitions about how cities evolve and contribute to debate by reducing the gap between some Jacobs' hypotheses and major theses.
\end{abstract}

Keywords: Economic Diversity, Industrial Pattern, Provincial Level

\section{Introduction}

The aim in this paper is to examine the economic structure and evolution of Italian provinces and test under what circumstances and to what extent economic diversity is positively associated with economic growth. At the theoretical level we rely on two distinct but strongly associated perspectives based on knowledge spillovers and the interpretation of the city as a nursery.

According to several authors, and much empirical evidence, the most important transfers of knowledge are inter-industry transfers [1-3]. From this perspective the variety and diversity of geographically proximate Industries, rather than industrial specialisation, promote innovation and growth. At the same time, some authors predict that firms located in areas that are highly industrially diversified should grow more quickly [4-8], for example, consider a representative set of cities and Industries over 18 years and show that the extent of diversity in the manufacturing industries in 1970 was crucial for attracting new or high-tech industries and creating the conditions for these new industries to flourish.

It is evident that the arguments proposed by [1,5] are essential to both these theoretical perspectives. According to this author cities are settlements whose growth is generated consistently from their own local economies: their pools of skills, manufactures and materials, at once diverse and concentrated, provide the best conditions for the birth and growth of entrepreneurial small firms and an ever-increasing division of labour on the basis of which "new work can be added to old" [9,1,10,5].

We investigate employment levels (for which data are available on such a large time span) of Italian provinces to measure their degree of economic diversity over the period 1951-2001. Using an index of entropy that accounts for both provincial size (in terms of number of employees) and time dimension, we test whether economic initiatives benefit from being localised in highly 
diversified (from an industrial point of view) areas. Note in this respect that our analysis is speculative in the sense that we rely on Jacobs' intuitions about how cities evolve and, de facto, make use of data collected at provincial level.

Analytically, economic diversity can be linked to growth based on three different interpretations of diversity: as a source of knowledge spillovers, as the concepttual basis for the city-nursery perspective (described above), and as a portfolio strategy to spread economic risk and, hence, protect a geographic area from external shocks $[11,12]$. We intend to find out which of these interpretations is more suitable to explain the association between diversity and growth in Italian provinces. Accordingly we investigate the industrial pattern that boosted growth and prosperity in the 20 largest provinces: depending on the nature of the industries dominating the local economic functions, and their degree of complementarity, we provide some qualitative insights supporting the city-nursery interpretation.

\section{The theoretical Roots of the Debate on Economic Diversity and Growth}

Economic diversity refers to the variety of the industrial activities within a certain geographic area. It contributes to the growth and evolution of cities: economic diversity enabled by proximity facilitates the transmission of ideas (through knowledge spillovers) and the outsourcing of activities (the city-nursery). Several empirical studies debate the fact that economic diversity is strongly associated with increased output and greater productivity and growth. [13], in a study of 79 American cities, find that the level of economic diversity in 1880 substantially affected output levels in 1890. [14] control for several variables (growth and variability of industries, relative composition of fast and slow growth industries, and relative mix of changing and stable industries) and show that, over the period 1969-1985, the industry mix of economies and their level of growth are positively associated. [15], on the other hand, suggests that geographic industry concentration (rather than industry diversification) enables knowledge spillovers among firms and local growth, based on evidence from computer chip manufacturers in Silicon Valley. [16] show that the concentration of economic activities (as measured by the density of employment) is positively correlated to GDP levels. There is some empirical evidence of specialization and intra-industry knowledge spillovers providing the basis for metropolitan growth [17], with some studies [18] considering the effects of both specialization and diversity [19].

How to support theoretically such a mixed evidence?
Many authors consider that inter industry knowledge exchange is more important than intra industry transfers [20,1-3,21,22]. In diversified economies there will be more interchange of different ideas, and this diversity is conducive to urban growth. [1] compares the economic structure and evolution of Manchester, a former textiles specialised city, which eventually declined, and Birmingham, a highly diversified city, which eventually flourished. [2] supports Jacobs by arguing that the diversity of urban activities automatically promotes attempts to apply or adopt in a particular field, technological solutions already utilised in another sector.

Jacobs' first intuition has been interpreted and elaborated by scholars to mean that because cities bring together people from different fields and areas, this fosters the transmission and, in turn, the cross-fertilisation of ideas across different activities, which is crucial for urban development.

An example here is brassiere manufacture, which evolved from the innovations made by dressmakers rather from than the lingerie industry [21]. Also, it is reported that the financial services industry grew out of intersectoral knowledge spillovers; more specifically, in New York, it developed from the recognition of grain and cotton merchants that there was a need for national and international financial transactions. Similarly, the practice of equipment leasing was initiated by a food processor in San Francisco (not by bankers). [20] discusses the spread of machine tools and describes how inventions or innovations spill over into different Industries, while [2] provides a detailed account of the sectoral source of inventions, estimating that some $70 \%$ of inventtions within a given sector are exploited outside that industry.

In line with the city-nursery perspective, some authors argue that firms located in areas that are highly industrially diversified should grow more easily [22,23,4,24,1, 5-7]. [9] stresses this aspect affirming that: "Although it is hard to believe, while looking at dull gray areas, or at housing projects or at civic centers, the fact is that big cities are natural generators of diversity and prolific incubators of new enterprises and ideas of all kinds. Moreover, big cities are the natural economic homes of immense numbers and ranges of small enterprises” [9:145].

That is, big cities are generators of diversity and incubators of new ideas, and are the natural economic home of several and various small firms. Jacobs emphasises the relevance of the urban dimension for small entrepreneurrial activities, arguing that small firms operating in a limited market, in many cases, require the presence of several services and inputs in order to outsource certain activities. In Jacobs' words: “Typically (small enter- 
prises) must draw on many and varied supplies and skills outside themselves, they must serve a narrow market at the point where a market exist, and they must be sensitive to quick changes in this market. Without cities, they would simply not exist” [9:145]. ${ }^{1}$

[21] compares New York and Pittsburgh in terms of their size, industrial structure and rate of growth, arguing that New York's evolution is linked to a more abundant supply schedule of entrepreneurship. In recognising that large areas are more diversified than small areas, Chinitz claims that diversified areas exhibit more stable growth because their fortunes are not tied to the fortunes of a few industries [21:281]. Likewise, [25] depict New York City as an incubator of new business activities and emphasise the constant rise and flow of new businesses as the main source of its de--velopment. ${ }^{2}$

In a study of small towns and rural areas [4] recognise their ability to provide various and more competitive "facilities" for industrial activities. As already mentioned, [8] investigate a representative group of cities and industries over the period 1970-1987, showing that diversity in manufacturing at the beginning of the period was a crucial factor in attracting new and high tech industries to the area and boosting their development.

\section{Measuring Economic Diversity and Employment Levels}

Thus, the idea that economic diversity facilitates the transmission of ideas and the outsourcing of activities is rooted in the theoretical and empirical economic literature. In this paper we provide an investigation to test whether, under what circumstances and to what extent, the diversity of economic activity explains how Italian provinces grow and evolve, based on data on employment levels in 47 economic sectors between 1951 and 2001.

We exploit Shannon's diversity index $\left(H_{t}{ }^{\prime} i\right)$ to measure the degree of diversity. This index, also known as the entropy index, is a statistics that measures the deviation of a given distribution from complete concentration (minimum entropy) or dispersion (maximum entropy). The entropy index measures the diversity of the economic structure against a uniform distribution of employment where the benchmark is an equi-proportional distribution of employment among all industries. The entropy index is used in numerous areas and typically is

\footnotetext{
${ }^{1}$ In his The Location of Economic Activity [22] gives the example of printing businesses, where typesetting used to be outsourced to compositors, and garment manufacture which relied on certain specialist services for particular steps in the process such as buttonhole making. ${ }^{2}$ [23] in Logic of British and American Industry describes how firms in large cities find it cheaper to 'farm out' certain functions to take advantage of scale economies, while firms in small places do not have this alternative and must do these jobs themselves.
}

calculated using the following formula:

$$
H_{t}^{\prime} i=-C * \sum_{j=1}^{n}\left[p_{j} * \log p_{j}\right]
$$

where $p_{j}$ is the relative proportion of employment in the $j$-th economic sector, $n$ is the number of sectors, $c$ is an arbitrary constant which determines the scale of measurement and $t$ is the relevant time interval. Under conditions of absolute diversity, the maximum value of $H_{t}{ }^{\prime} i$ for the i-th province is obtained; minimum entropy or complete specialisation is indicated if only one of the $p_{i}$ sector equals 1 and the remainder are zero. We calculate seven measures of entropy $\left(H_{51}{ }^{\prime} i, H_{61}\right.$ 'i, $H_{71}$ 'i, $H_{81}$ ' $i$, $H_{91}$ ' $i, H_{96}$ ' $i$ and $H_{01}$ ' $i$ ), one for each year in our dataset (1951, 1961, 1971, 1981, 1991, 1996 and 2001) ${ }^{3}$.

We measure employment levels as number of employees in the $i$-th province at time $t$ between 1951 and 2001: emp $p_{51} i, e m p_{61} i, e m p_{71} i, e m p_{81} i, e m p_{91} i, e m p_{96} i$ and $e m p_{01} i$. Use of employment levels is imposed by data availability and suggested as being appropriate by [26] according to whom employment growth is seen as particularly appropriate to explain the impact produced by diversity. Knowledge spillovers, in effect, will facilitate radical innovation and product innovation which, in turn, will lead to the creation of new markets and more employment; similarly, according to the city-nursery perspective, cities will attract new entrepreneurial initiatives which strictly are accompanied by additional employees.

After normalising the values of $H_{t}^{\prime} i$ between 0 and 1 , we compute a dynamic measure of entropy $\left(D H_{k}^{\prime} i\right.$ ) to account for a specific hypothesis: diverse industrial patterns generate effects over the time. The presence of diverse economic activities at a given initial time period ( $t$ $=1$ ) will directly generate more diverse economic active- ties at $t=2$ and will continue positively and indirectly to affect the degree of economic variety at the following time periods ( $t=3, t=4, t=5$, etc.)]. Accordingly $D H_{k}{ }^{\prime} i$, for $k=\{1, \cdots t\}$, is given by the cumulative sum for $t=\{1, \cdots 7\}$ of the $H_{t}{ }^{\prime} i$

$$
D H_{k}^{\prime} i=\sum_{t=1}^{7} H_{t}^{\prime} i
$$

We get seven $\mathrm{DH}_{k}{ }^{\prime} i$, one for each observed year. Relying on the fact that the positive effects that economically diverse provinces produce are generally amplified by the dimension of the local economy, we propose to

${ }^{3}$ We use the inverse of the Herfindahl index ( $H$ is, per se, a measure of industry concentration) to find support for the ranking provided by the entropy measure. As is well known, the $H_{t} i$ index is

$$
H_{t} i=\sum_{j=1}^{n}\left(p_{j} * 100\right)^{2}
$$

where $p_{j}$ is the number of employees in the $j$-th sector, and $n$ is the total number of sectors. Most of the records in the rankings overlap (compare $1^{\text {st }}$ and $2^{\text {nd }}$ columns in table 5 in the Annex). 
include the size of provinces $\left(D D H_{k}^{\prime} i\right)^{4}$. Formally, $D D H_{k}^{\prime} i$ are the $D H_{k}^{\prime} i$ weighted by the number of employees $(e m p i)$ :

$$
D D H_{k}^{\prime} i=e m p_{t} i * D H_{k}^{\prime} i
$$

We estimate the association per province and over time between the seven $D D H_{k}^{\prime} i$ and the seven values of employment $\left(e m p_{t} i\right)$ at each time $t$. It is interesting to notice that most Italian provinces show a positive and very high correlation coefficient: it is higher than 0.90 in 64 provinces and over 0.50 in 74 provinces (see Figure 1): increased diversity is accompanied by increased employment.

Only 19 provinces have a negative and significant (below -0.50) correlation coefficient (i.e., employment level per province is inversely associated to the evolution of its diversity).

The provinces that experienced a highly correlated evolution of both degree of diversity and employment levels are Milano $\left(1^{\text {st }}\right)$, Bergamo, Frosinone, Mantova, Parma, Ascoli Piceno, Bari, Como, Teramo and Brescia (see Table 1). Note that here we are not looking at the mere correlation between economic diversity and provincial size at a given time and that the above group in cludes not only large but also medium and small provinces. While changes in diversity and employment levels are negatively associated over the time for Isernia (ranked last), Pavia, Genova, Trieste, La Spezia, Savona, Gorizia, Vercelli, Alessandria and Verbano.

\section{Economic diversity and the recurrent pattern of economic functions}

We also want to investigate empirically [9] claim that: "To understand cities, we have to deal outright with combinations or mixtures of uses, not separate uses, as the essential phenomena" [9: 144]. That is, in order to study geographic areas, we need to focus on the several relationships among economic activities, their combination and the cross fertilisation processes that occur within the local economic structure. We focus on the largest, in terms of employment levels, provinces at 2001.

\footnotetext{
${ }^{4}$ In our view the relevance of the urban size and temporal dimension is typified in [4,24]. [4:136] refer to the fact that even in underindustrialized areas exhibiting slower growth, ultimately there will be enough business to justify the establishment of a sheet metal shop, a truck depot, etc., which eventually will result in a 'critical mass of industrial facilities' which enables accelerated economic growth. [24:288] describes how the agglomeration of industries and firms is based on the greater availability of goods and services related to the dominant Industry. The author gives the example of transportation, a service established based on the needs of a dominant industry, whose availability attracts other industries to the area based on its lower cost compared to other territories. These additional industries benefit also from the community of business service suppliers in the area, e.g. legal, accounting, printing, etc.
}

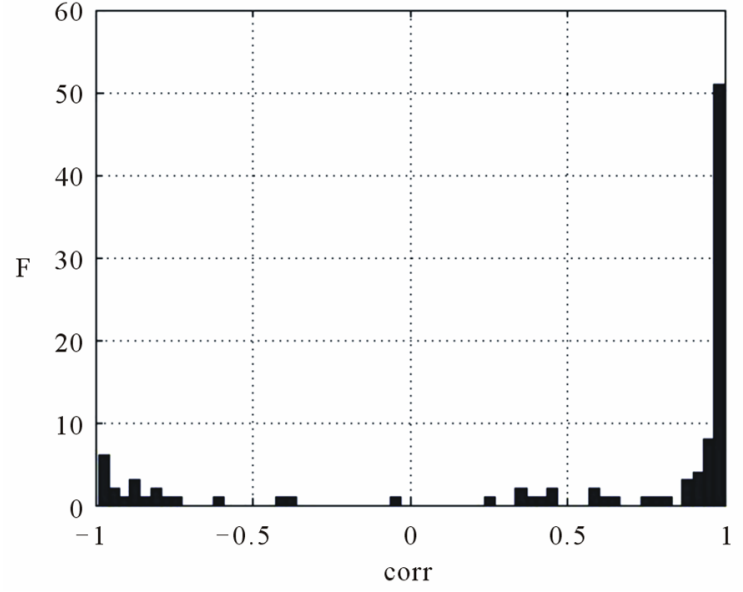

Figure 1. Frequency distribution of correlation between $D D H^{\prime}{ }_{k} i$ and $e m p_{t} i$, Source: Own elaboration on ISTAT database (2001).

Table 1. Correlation between $\mathrm{DDH}_{k}{ }_{k} i$ and $e m p_{t} i$ per province, 1951-2001.

\begin{tabular}{|c|c|c|c|c|c|}
\hline Agrigento & -0.735 & Genova & -0.983 & Potenza & 0.980 \\
\hline Alessandria & -0.936 & Gorizia & -0.958 & Prato & 0.971 \\
\hline Ancona & 0.990 & Grosseto & -0.871 & Ragusa & 0.932 \\
\hline Aosta & -0.885 & Imperia & -0.058 & $\begin{array}{c}\text { Ravenna } \\
\text { Reggio }\end{array}$ & 0.925 \\
\hline Arezzo & 0.982 & Isernia & $\mathrm{NaN}$ & $\begin{array}{c}\text { di Calabria } \\
\text { Reggio }\end{array}$ & -0.861 \\
\hline Ascoli Piceno & 0.997 & La Spezia & -0.971 & nell’Emilia & 0.992 \\
\hline $\begin{array}{l}\text { Asti } \\
\text { vellino }\end{array}$ & $\begin{array}{l}0.405 \\
0891\end{array}$ & L Aquila & 0.940 & $\begin{array}{c}\text { Rieti } \\
\text { Rimini }\end{array}$ & $\begin{array}{r}-0.593 \\
0.969\end{array}$ \\
\hline Bari & 0.997 & & 0.996 & & 0.985 \\
\hline Belluno & 0.976 & Lecco & 0.974 & Rovigo & 0.986 \\
\hline Benevento & 0.467 & Livorno & -0.781 & Salerno & 0.985 \\
\hline Bergamo & 0.998 & Lodi & 0.580 & & 0.996 \\
\hline Biella & 0.599 & Lucca & 0.994 & Savona & -0.965 \\
\hline Bologna & 0.984 & Macerata & 0.994 & Siena & 0.928 \\
\hline Bolzano-Bozen & 0.982 & Mantova & 998 & & 0.975 \\
\hline Brescia & 0.996 & Massa-Carrara & -0.816 & Son & .956 \\
\hline Brindisi & 0.983 & Matera & 0.982 & Tarc & 0.991 \\
\hline Cagliari & 0.386 & Mess & -0.368 & Teramo & 0.997 \\
\hline Caltanissetta & -0.810 & & & & -0.837 \\
\hline Campobasso & 0.966 & Mo & 990 & & 0.346 \\
\hline & 0.95 & & & & -0.409 \\
\hline Catan & 0.92 & No & & & 0.903 \\
\hline Catanzaro & 0.876 & Nuo & 987 & Treviso & 0.991 \\
\hline Chieti & 0.996 & Orist & 941 & & -0.974 \\
\hline Como & 0.997 & dova & 0 & dine & 0.990 \\
\hline Cosen & 0.249 & Palermo & 0.755 & Tarese & 0.976 \\
\hline Cremona & 0.346 & arma & 0.998 & Venezia & 0.989 \\
\hline Crotone & 0.776 & Pavia & -0.990 & Verbano-C-O & -0.924 \\
\hline Cuneo & 0.950 & $\begin{array}{l}\text { Perugia } \\
\text { Pesaro }\end{array}$ & 0.995 & Vercelli & -0.951 \\
\hline Enna & 0.438 & e Urbino & 0.988 & Verona & 0.991 \\
\hline Ferrara & 0.6 & Pesc & 995 & Vibo Valentia & 0.808 \\
\hline Firenze & 0.989 & Piacenza & & & 0.993 \\
\hline Foggia & 0.877 & Pisa & 0.975 & Viterbo & 0.940 \\
\hline Forli-Cesena & 0.973 & Pistoia & 0.954 & & \\
\hline Frosinone & 0.998 & Pordenone & 0.969 & & \\
\hline
\end{tabular}

Source: Own elaboration on ISTAT database (2001). 
[9] describes this as: "But although cities may fairly be called natural economic generators of diversity and natural economic incubators of new enterprises, this does not mean that cities automatically generate diversity just by existing. They generate it because of the various efficient economic pools of use that they form. Wherever they fail to form such pools of use, they are little better, if any, at generating diversity than small settlements... At the other extreme, huge city settlements of people exist without their presence generating anything much except stagnation and, ultimately a fatal discontent with that place... Rather, something is wrong with their districts; something is lacking to catalyze a district population's ability to interact economically and help form effective pools of use" [9:148].

Based on this, first we observe the evolution of $\mathrm{H}_{t}^{\prime}{ }^{i}$ over the time span 1951-2001 in the largest provinces and in the smallest ones (Figure 2a, b). In the first group, 18 provinces show high levels of entropy (above 0.5,

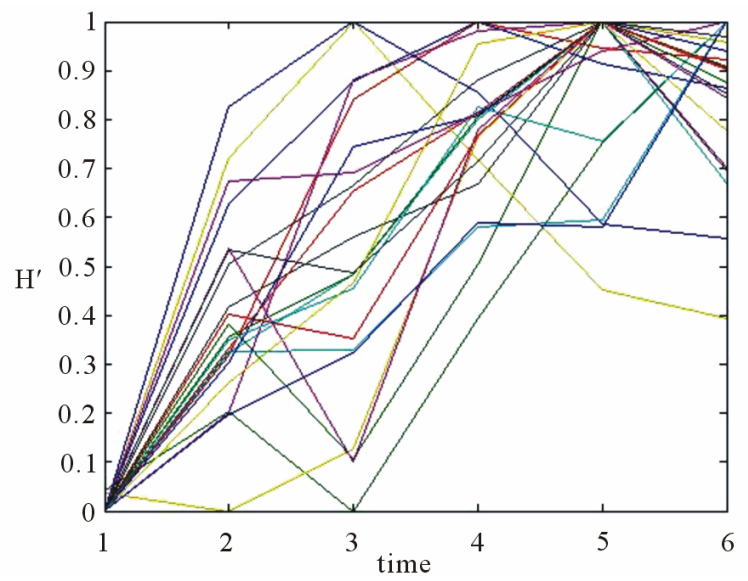

(a)

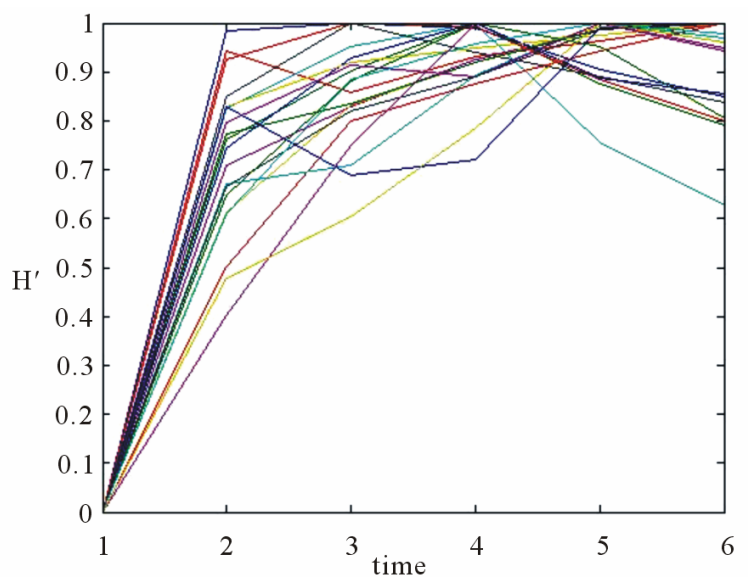

(b)

Figure 2. (a, b) Economic diversity in the 20 largest (a) and 20 smallest (b) provinces over the time period 1951-2001, Source: ISTAT database (2001). normalised values) in 1961, while the process of increasing diversification is much slower in small provinces.

Figure 3 (a) shows that in 1961 large provinces present a more important economy and some basic Industrial sectors (code and number of employees): retailing (code $=16, \mathrm{n}^{\circ}$ employees $\left.=749,978\right)$, constructions $(19$, $441,960)$, non electric machines, metallic carpen- try and foundries $(30,369,459)$, wholesale trade $(17,227,673)$, hotels and restaurants $(4,220,390)$, ma- chines and repair plants (40, 198,791), clothing Indus- try $(1,181,978)$, food and beverages (5, 164,830), electric machines for communications $(29,152,939)$, non metal-bearing minerals $(37,151,677)$, chemicals $(15,146,464)$, metallurgy (34, 137,098), communica- tions $(18,105,140)$, wood industry $(27,104,823)$, shoes industry $(12,92,706)$, credit $(20,87,497)$, other services to transport (9, 79,946).

In the smallest provinces, the industrial pattern is less important and less diverse. Only a few sectors in this

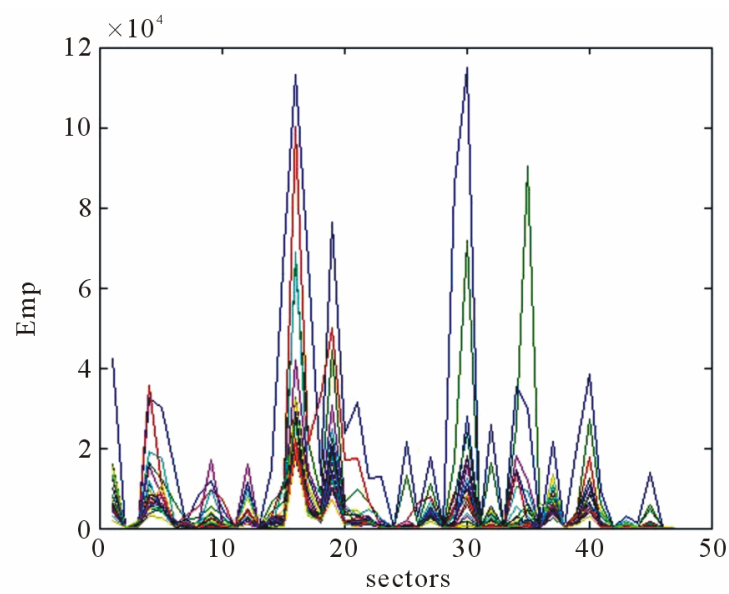

(a)

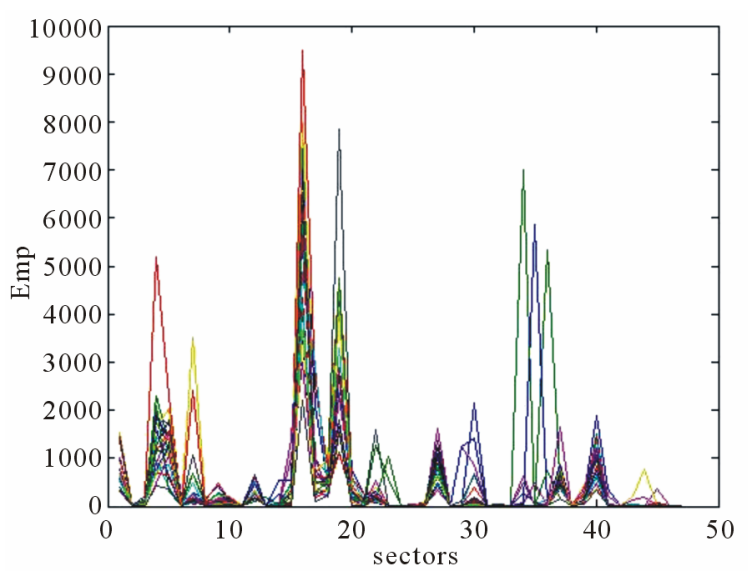

(b)

Figure 3. (a, b)The economic pattern of the 20 largest (a) and 20 smallest (b) provinces in 1961, Source: ISTAT database (2001). 
group are shown to be relevant: retailing $(16,111,748)$, constructions $(19,61,594)$, hotels and restaurants (4, $30,551)$, food and beverages $(5,25,286)$, machines and repair plants $(40,19,306)$, clothing industry $(1,17,034)$, wood industry $(27,16,947)$, wholesale trade $(17,16,765)$ and non metal-bearing minerals $(37,12,637)$.

Large provinces are also characterised by a strong correlation between some blocks of economic activities compared to small ones (see the graphical representation of correlation matrices in Figure 4). We use the correlation matrix of employment levels in each sector to better identify similarities in terms of number of employees in both sets of provinces. We obtain two $47 \times 47$ matrices whose $i, j$ entry is $\operatorname{corr}\left(e m p_{i}, e m p_{j}\right)$, that is, the coefficient of correlation between the employment level in the $i$-th sector and the number of employees in the $j$-th sector.

Large provinces show a clear economic configuration that is defined by a "recurrent" industrial pattern: aside from hotels and restaurants and food and beverages, there are retailing, wholesale trade, communication, constructions, credit and other services to transport, machine

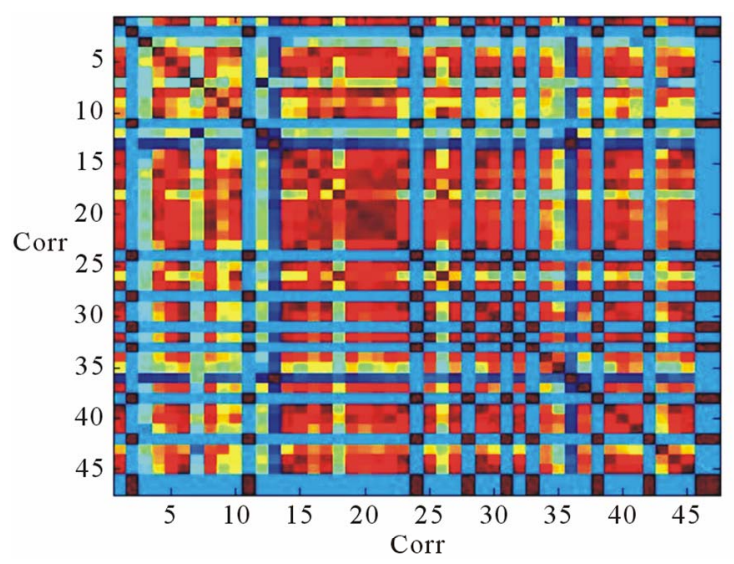

(a)

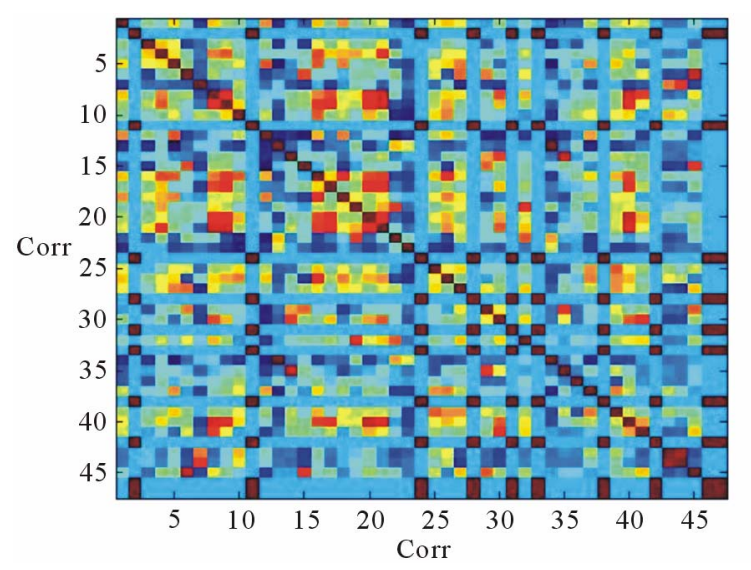

(b)

Figure 4. (a, b)Correlation matrix for the largest (a) and smallest (b) provinces, Source: ISTAT database (2001). and repair plants are all correlated sectors (see red areas in Figure 4). This result seems surprising since large provinces are generally characterised by high levels of entropy, often used in biology as a measure of disorder. In contrast, small provinces' industry structures, which have low levels of entropy, conform less to a common sectoral pattern.

Since correlation does not mean complementarity we attempt some preliminary qualitative reasoning. A substantial difference between diversity meant as 1) the source of knowledge spillovers, 2) basis for the city-nursery and 3) source of a portfolio of economic activities (which protect the relevant geographic area from external shocks) is given by the degree of complementarity among industrial activities: the concept of the city-nursery assumes that economic sectors are sufficiently complementary to provide the basic goods and services required for new entrepreneurial initiatives while the portfolio theory is based on their diversification and lack of interdependence. Moreover, although knowledge spillovers may occur between very diverse (i.e., not interrelated) industries, they are more likely in sectors where people meet to discuss common problems.

The first two theoretical perspectives were discussed in the introduction and in section 2. According to the portfolio argument, economic diversity could be seen as a strategy to spread risk, in order to protect a region from external demand shocks (similar to a strategy of corporate diversification). High sectoral diversity in the regional economy implies that a negative demand shock in any of these sectors will have only moderately negative effects on growth. On the other hand, a geographic area specialising in one sector (or group of sectors with related demand) is at risk of serious slowdown in growth, and high rates of unemployment [26].

Given the predominantly "instrumental” (or “facility”) nature of the economic activities characterising the industry pattern in large provinces (including retailing and wholesale trade, constructions and wood industry, non electric machines, machines and repair plants and electric machines for communications, non metal-bearing minerals and metallurgy, metallic carpentry and foundries, chemicals, communications, credit and other services to transport) we can assume a reasonable degree of complementarity and, hence, argue i favour of the interpretation of the city as nursery.

\section{Conclusions}

The economic analysis in this paper investigates whether, under which circumstances and to what extent diversity of economic activities explains how Italian provinces grow and evolve. We made use of a measure of entropy 
to account for two specific hypotheses: first, diverse industry patterns generate effects over the time; secondly, the positive effects of economically diverse provinces on economic growth are amplified by the size of the province.

We estimated the association per province and over the time between our proposed index $\left(D^{2} H_{k}{ }^{\prime} i\right)$ and employment levels. We found positive and very high results for most provinces (64 provinces have a correlation coefficient higher than 0.90), while only 19 have a negative and significant correlation coefficient.

We also investigated empirically Jacobs' assertion that to understand cities we need to take direct account of the various efficient economic pools. Lacking information at urban level, we made use of data collected at provincial level.

We focused on the recurrent industrial pattern at 1961 that worked to boost growth in the largest provinces. In 1961 large provinces hosted more important economies and a more industrially diversified pattern compared to small provinces which had less important and less diversified industrial structures. Only a few sectors were important in small provinces. We find also that large provinces are characterised by highly correlated blocks of economic activities, despite large provinces are generally characterised by high levels of entropy (or disorder). The industrial structures in small provinces, on the other hand, tend not to conform to a common pattern.

Given that economic activities characterising the industrial pattern of large provinces play as key-facilities (e.g., retailing and wholesale trade, constructions and wood industry, chemicals, communications, credit and other services to transport) we showed that there is a fairly high degree of complementarity supporting citynurseries, and to a lesser extent knowledge spillovers, rather than the portfolio argument on economic activities at local level.

\section{Reference}

[1] Jacobs, J. (1969a) The Economy of Cities. Random House, New York.

[2] F. M. Scherer, "Inter-Industry Technology Flows In The United States” Research Policy, Vol. 11, No. 4, 1982, PP. 227-45.

[3] Bairoch, P. (1988) Cities and Economic Development: from the Dawn of History to the Present. University of Chicago Press, Chicago.

[4] B. J. Chinitz, R. Vernon, "Changing Forces In Industrial Location,” Harvard Business Review, Vol. 38, No. 1, 1960, PP. 126-136.

[5] Jacobs, J. (1984) Cities and the Wealth of Nations: Principles of Economic Life. Random House, New York.

[6] G. Duranton, D. Puga, "Diversity and Specialisation in
Cities: Why, Where and When Does it Matter?,”Urban Studies, Vol. 37, No. 3, 2000, PP. 533-555.

[7] G. Duranton, D. Puga, "Nursery Cities: Urban Diversity, Process Innovation, and the Life-Cycle of Products," American Economic Review, Vol. 91, No. 5, 2001, PP. 1454-1477.

[8] J. V. Henderson, A. Kuncoro and M. Turner, "Industrial development in cities,” Journal of Political Economy, Vol.103, No. 5, 1995, PP. 1067-1090.

[9] Jacobs, J. (1961) The Death and Life of Great American Cities. Vintage Books, New York.

[10] J. Jacobs, "Strategies for Helping Cities," American Economic Review, Vol. 59,No. 4, 1969b, PP. 652-656.

[11] M. Attaran, "Industrial Diversity and Economic Performance in U.S. Areas," Annals of Regional Science, Vol. 20, No. 2, 1986, pp. 44-54.

[12] P. Haug, „Diversifikation und regionale Wirtschafts- und Beschäftigungsentwicklung - Eine empirische Analyse für ausgewählte deutsche Gebiete“, Jahrbuch für Regionalwissenschaft, Vol. 24, No. 2, 2004, PP. 177-195.

[13] R.W. Bostic, J.S. Gans and S. Stern, "Urban Productivity and Factor Growth in the Late $19^{\text {th }}$ Century," Journal of Urban Economics, Vol.4, No.1, 1997, PP. 38-55.

[14] T. Garcia-Mila, T.J. McGuire, "Industrial Mix as a Factor in the Growth and Variability of States' Economies," Regional Science and Urban Economics, Vol. 23, No. 6, 1993, PP. 731-48.

[15] W. B. Arthur, "Silicon Valley locational clusters: do increasing returns imply monopoly?” Mathematical Social Sciences, Vol. 19, 1990, PP. 235-251.

[16] A. Ciccone, R.E. Hall, "Productivity and the Density of Economic Activity," American Economic Review, Vol. 86, No.1, 1996, PP. 54-70.

[17] U. Lim, “Knowledge Externalities, Spatial Dependence, and Metropolitan Economic Growth in the United States," Environmental and Planning A, Vol. 39, No.4, 2007, PP. 771-788.

[18] N. A. Phelps, "From Branch Plant Economies to Knowledge Economies? Manufacturing Industry, Government Policy, and Economic Development in Britain's Old Industrial Regions," Environment and Planning C: Government and Policy, Vol.27, No. 4, 2009, PP. 574-592.

[19] C. Beaudry and A. Shiffauerova, "Who's right, Marshall or Jacobs? The Localization Versus Urbanization Debate," Research Policy, Vol. 38, No. 2, 2009, PP. 318-337.

[20] N. Rosenberg, "Technological Change in the Machine Tool Industry, 1840-1910,” Journal of Economic History, Vol. 23, No. 4, 1963, PP. 414-443.

[21] E. L. Glaeser, H. Kallal, J. Scheinkman and A. Shleifer, "Growth In Cities," Journal of Political Economy, Vol. 100, No. 6, 1992, PP. 1126-1152.

[22] Hoover, E. M. (1948) The Location of Economic Activity. McGrawHill, New York. Van Oort F. G. (2004). Urban Growth and Innovation. Spatially Bounded Externalities in the Netherlands. Ashgate, Aldershot.

[23] Florence, S. P. (1953). The logic of British and American 
industry. Routledge, London.

[24] B. J. Chinitz, "Contrasts in Agglomeration: New York and Pittsburgh," American Economic Review, Vol. 51, 1961, PP. 279-89.

[25] Hoover E.M. and Vernon R. (1959) Anatomy of a Me- tropolis. Cambridge, MA: Harvard University Press.

[26] K. Frenken, F.G. van Oort and T. Verburg, "Related Variety, Unrelated Variety and Regional Economic Growth," Regional Studies, Vol. 41, No. 5, 2007, PP. 685-697. 